\title{
Escola e polícia em três países: vinho novo em odres velhos ou a crise das instituições ${ }^{1}$
}

\author{
João Casqueira Cardoso* \\ Candido Alberto Gomes** \\ Edna Ugolini Santana***
}

\section{Resumo}

A amplitude internacional das violências nas escolas tem levado à presença cada vez maior dos policiais nos estabelecimentos de ensino. Este trabalho analisa as pontes entre escola e polícia no Brasil, Portugal e França, em tempos de crise institucional da chamada pós-modernidade. Neste cotejo verifica-se que tais relações correspondem ao quadro constitucional e administrativo de cada país, sendo as normas reinterpretadas na realidade social, afastando-se com frequência do tipo ideal burocrático. Nesta dinâmica, se verificam arriscados desvios e superposições de papéis de educadores e agentes. Diversos projetos têm buscado, com maior ou menor sucesso, superar a distância entre policiais e jovens, cujos papéis sociais e aparências os opõem sob a lente de estereótipos, em parte fundamentados em fatos. Propõem-se rumos para novas pesquisas.

Palavras-chave: Polícia. Segurança Escolar. Violência escolar. Gestão escolar. Preconceitos.

\section{Introdução}

Hoje a presença da polícia em escolas tende a ser desejada em numerosos países do mundo como garantia de segurança de educadores e estudantes. Já vai longe o tempo em que a polícia era abominada por entrar na escola e, em particular, na universidade por reprimir manifestações políticas. Conta-se que certa vez, nos anos 1960, o Magnífico Reitor Pedro Calmon foi chamado com urgência, pois a polícia estava a ponto de invadir a então Faculdade Nacional de Direito, no Rio de Janeiro, em frente à qual os estudantes faziam mais um candente protesto. Calmon, altivo, com os seus cabelos brancos, orador

\footnotetext{
Pesquisa realizada pela Cátedra UNESCO de Juventude, Educação e Sociedade da Universidade Católica de Brasília.

* Doutor em Direito pelas Universidades de Paris X - Nanterre e de Florença Mestre em Estudos Internacionais pela Universidade de Reading. E-mail: jcasq@ufp.pt

** Doutor em Educação pela Universidade da Califórnia, Los Angeles. E-mail: clgomes@terra.com.br

*** Mestre em Educação pela Universidade Católica de Brasília. E-mail: ednaugolini@gmail.com
} 
primoroso, exclama para o comandante da tropa: "Mas o senhor não pode entrar na Faculdade!". O comandante the retruca que tem ordens superiores para isso, ao que o Reitor, tranquilo, coloca um ponto final: "Meu filho, na Faculdade só se entra com vestibular". (DIREITO, [2010?], p. 3).

Tais eram os tempos quando mal despontava a crise de instituições esculpidas pela e para a modernidade, como a escola. Não se falava de crise do sentido, mal estar, emergência da subjetividade e protagonismo (adolescente e juvenil), nem de desencontro entre os valores, objetivos, estruturas e resultados das instituições e os dos seus atores, nem do declínio da instituição (DUBET, 2002), no contexto da chamada pós-modernidade. A fragmentação e a nebulosidade de valores e, em decorrência, de normas, entre outros aspectos, geraram uma miríade de incompatibilidades, cuja metáfora mais aproximada seria a do vinho novo em odres velhos, embora também se abrigue vinho velho em odres novos. A violência é uma dos matizes das sociedades hoje, incluindo a escola, com tradição milenar de violência institucional, para a qual a violência dos alunos, muitas vezes como revide, ainda aparece como escandalizadora surpresa, confirmando que pimenta nos olhos dos outros é refresco. A escola para todos, legitimada pelos altos valores que germinaram na Ilustração e no Iluminismo, criou uma armadilha, que, entretanto, não invalida a democratização: escola para todos é aquela em que muitos lá estão obrigados, por tempo cada vez mais longo, e da qual uns sairão "incluídos" e outros, não poucos, "excluídos". Como nem os escravos aceitavam passivamente a sua sina, na sociedade do consumo fluente, não é raro que o aborrecimento e o fracasso dos alunos e, em seguida, também dos educadores sejam retrucados com a violência simbólica e física, o que a explica, mas não a justifica. Assim, não é raro constatar que, ao contrário dos tempos do Magnífico Reitor Pedro Calmon, o "sonho" de muitos educadores é contar com a presença permanente da polícia na escola, o que coloca em questão funções e estereótipos opostos. Adolescentes e jovens exercem protagonismo e rebeldia, enquanto policiais representam um aparelho repressivo para manter a ordem. Neste jogo de espelhos cruzados e distorcidos, policiais e jovens, bem como policiais e educadores têm culturas diferentes que podem levar a conflitos, inclusive de competências. Há situações em que a polícia só age dentro da escola com autorização do diretor, outras em que os policiais, chamados, levam a efeito procedimentos padrões capazes de gerar até questões judiciais por ferirem a lei, em especial o Estatuto da Criança e do Adolescente (Lei 8069, de 13 de Julho de 1990, em vigor no Brasil). Por outro lado, a escola, não tão democrática, mas 
institucionalmente violenta desde o seu berço, clama pela polícia para restabelecer a ordem ante a iminência de os odres se romperem e o vinho se derramar ou de eclodir a panela de pressão, precariamente mantida.

Longe de ser exaustivo, este trabalho faz um bosquejo de experiências, em especial do Brasil, Portugal e França, onde emergem antinomias dificeis de solucionar, entre valores e concepções de papéis profissionais que mais parecem água e azeite. Buscase, como em trabalhos prévios, iluminar estas contradições, ainda que se mantenha uma penumbra, a ser dissipada, segundo a esperança, por novas pesquisas e práticas.

\section{Violência escolar pandêmica}

Numerosas pesquisas indicam que a violência nas escolas é um problema mundial (DEBARBIEUX, 2006), motivador de uma torrente de estudos e projetos. As formas mais usuais envolvem depredações, furtos e roubos de objetos pessoais e do patrimônio, além de agressões entre alunos e professores, chegando às brigas entre gangues dentro e fora das escolas, rixas, tráfico e consumo de drogas e uso de armas brancas e de fogo. Dentre inúmeras investigações, Gomes e colaboradores (2006) concluíram que a violência é "democrática", presente tanto em escolas públicas quanto particulares, mas com expressões e formas de tratamento diferentes. Alunos da educação básica crescem e se tornam estudantes da educação superior, para lá conduzindo as incivilidades e as formas julgadas prontas e eficazes de provocação e "resolução" de conflitos (CALDAS, 2012). Em face de tudo isso, profissionais da educação se percebem despreparados para lidar com esses problemas (GONÇALVES; SPÓSITO, 2002). Não por acaso, têm sido tomadas medidas nos últimos anos para superar a violência, como: 1) a recusa em matricular alunos que possuem histórico violento ou que venham transferidos de outras escolas por terem cometido algum ato ilícito (ARROYO, 2007, p. 2) a implantação de equipamentos de segurança, como alarmes, câmeras de vigilância e outros (DEVINE, 2002; COON, 2005) e a presença de policiais armados na escola (THOMAS; SMITH, 2004). Porém, nenhuma dessas medidas garante efetiva diminuição da violência nas escolas. No labirinto de desafios novíssimos e soluções pouco eficazes, sem Ariadne e sem Teseu, não podendo resolver os conflitos, chama-se não só a polícia, mas também a justiça. Com isso, os conflitos são decididos por outrem, fora da escola, promovendo a sua aparentemente crescente judicialização (CHRISPINO; CHRISPINO, 2008). É bem verdade que se espera muito mais da escola do que ela pode oferecer, já que, 
ao se tornar instituição para todos, importa da sociedade a gama de diversidades e questões sociais que marcam os tempos, como as recomposições familiares, a pobreza, o desemprego juvenil, a precariedade das relações trabalhistas, o uso e tráfico de drogas, a criminalidade, inclusive a transnacionalização do crime organizado, e tantas mais que cabem aos órgãos encarregados da economia, do trabalho, dos assuntos sociais, da segurança pública e outros. Dar a César o que é de César, no caso da escola, significa definir e esperar o que ela efetivamente pode cumprir, delimitando as funções de outras organizações. Não lhe cabe tanto, mas o que é dela típico (CHRISPINO; LAMEGO, 2012). As crises tornam as fronteiras institucionais cambiantes e difusas, mas nada se fará para superar a crise se elas não forem fixadas, ainda que temporariamente, de modo que cada uma exerça seriamente as suas responsabilidades.

\section{Pontes escola - polícia em três países}

Em face dos problemas de segurança, diversos países têm buscado construir pontes entre a escola e a polícia, inclusive por meio de projetos específicos, uma vez que são patentes as oposições entre as duas instituições e entre jovens e policiais. Para isto, selecionaram-se Portugal, a França e o Brasil, embora este último, pelas dimensões e diversidades, abrigue múltiplas experiências. Note-se que os contextos sociais e político-constitucionais são diferentes e interessantes. Como realçado num trabalho anterior, "a comparação de sistemas tem como efeito a luta contra o "chauvinismo" jurídico, incitando a uma maior abertura e espírito curioso necessário a qualquer aprendizagem". (CARDOSO, 2004, p. 146).

Qual a situação em Portugal? Antes de mais, importa realçar a multiplicidade das forças policiais com competência para intervir nas escolas. Essas forças policiais são três: a Polícia de Segurança Pública (PSP), a Guarda Nacional Republicana (GNR), e a Polícia Municipal. Importa realçar o estatuto específico, de cariz militar, da GNR. Quanto à Polícia Municipal, existe apenas em 32 dos 308 municípios de Portugal (uma maioria de 21 localizando-se no Norte de Portugal, as restantes no Centro e Sul). O maior número de intervenções junto das escolas diz respeito à PSP, mais especificamente através do Programa "Escola Segura", cuja origem se encontra num protocolo celebrado em 1992 entre o Ministério da Administração Interna e o Ministério da Educação. Trata-se de um programa com uma vertente essencialmente preventiva e pedagógica (a PSP especializou-se nessas ações pedagógicas, com mais de 3000 "acções de sensibilização/formação/demonstrações/exercícios de prevenção", 
desenvolvidas em colaboração com as escolas e autarquias no período de 2007-2008 (POLÍCIA DE SEGURANÇA PÚBLICA, [2010?]).

O Ministério da Educação, por sua vez, mantém na escola vigilantes vinculados ao Gabinete Coordenador de Segurança Escolar, enquanto o Ministério da Administração Interna age na área envolvente, através das equipes do programa Escola Segura. As duas entidades são constituídas por agentes (ou ex-agentes, no caso do Gabinete Coordenador de Segurança Escolar) das forças de segurança. No Gabinete de Segurança Escolar, entre os funcionários recrutados estão antigos policiais e professores, com média de idade de 27 anos, escolhidos com a ajuda de um Comissário de Polícia. A prática de artes marciais é uma das exigências feitas quanto ao preparo físico. No que concerne às equipes policiais móveis de segurança, inspiradas na experiência francesa, têm como maiores missões evitar invasões de escolas, prevenir lutas entre alunos e combater a circulação e o consumo de drogas (PORTUGAL, [2011?]).

Contudo, as forças policiais (PSP bem como GNR e Polícia Municipal), não têm uma ação notável no plano interno das escolas em Portugal. Antes pelo contrário, as suas ações concentram-se nos espaços públicos envolvendo as escolas, com destaque para ações de fiscalização das vias de circulação de veículos (estacionamento, excessos de velocidade, inter alia).

Pelo menos dois fatores explicam esta timidez de intervenção das Polícias junto das escolas: primeiro, deve-se à separação das competências ministeriais (Administração Interna, por um lado; Educação, pelo outro). A este elemento junta-se a ausência de órgãos de decisão política intermediária entre o poder central e as escolas (como é o caso no Brasil com os Estados federados) e consequentemente a aparente ausência de necessidade de controle, acrescido das normas uniformes provenientes do poder central - no caso do Brasil, do poder federal; segundo, o passivo democrático português (regime salazarista de 1926 a 1974) explica que qualquer intrusão das forças de segurança no espaço escolar (e, a fortiori, universitário) seja sentida como um potencial entorce à democracia.

Em caso de indisciplina ou de violência, as escolas preenchem um formulário eletrônico, enviado ao Gabinete Coordenador de Segurança Escolar, do Ministério da Educação. Todas as situações eram acompanhadas, de modo a alertar os parceiros e a agir preventivamente, quando possível, ou reativamente, em face de uma ocorrência concreta. 
Cabe ao Observatório da Segurança Escolar triar e analisar as comunicações eletrônicas dos estabelecimentos educacionais, efetuando diagnósticos e programas de prevenção da indisciplina e de manutenção da segurança escolar (SEBASTIÃO; ALVES; CAMPOS, 2011). Com os drásticos cortes orçamentários, o referido Gabinete foi extinto em 2012 e suas atribuições integradas na Direcção-Geral da Educação.

Por sua vez, a França conta com várias polícias, embora com as missões mais claramente definidas. Para o propósito da segurança escolar atuam: 1) a Gendarmerie Nationale, encarregada da segurança das áreas rurais e aglomerações urbanas menores; 2) a Polícia Nacional, responsável pela Capital e pelas cidades de mais de dez mil habitantes. Desde 1990, com o agravamento das violências escolares, em especial nas áreas de maior exclusão social, têm sido estatuídas parcerias entre a Polícia, a Justiça e a Educação, particularmente entre os Ministérios da Educação Nacional e do Interior. Claro que as parcerias, estabelecidas pelo governo central, podem alcançar resultados muito variáveis ao nível local. A polícia tanto pode ser solicitada pelo diretor escolar, como pode tomar a iniciativa de conduzir uma operação de segurança numa escola. Em princípio, aatuação policial deveobteroassentimento do diretor da escola, porém os meios de comunicação de massa informam sobre situações que ultrapassam os limites se não legais, pelo menos do bom senso. Desde um acordo de 2004, em cada circunscrição policial, brigada de proximidade ou comunidade de brigadas incluindopelomenos um estabelecimento educacional deveser designado um correspondente policial ou gendarme referente, que é o interlocutor da direção escolar. Por sua vez, o diretor de estabelecimento é o representante do Estado no âmbito da unidade escolar, cabendo-lhe manter a ordem pública, a higiene e a salubridade.

Diversos programas e projetos de segurança escolar têm sido adotados nas últimas décadas. Presentemente, atuam nas áreas mais sensíveis ou vulneráveis as equipes móveis de segurança escolar, nos arredores da escola e à disposição para intervir na unidade escolar, se necessário. Tanto os agentes quanto os diretores têm recebido formação específica para atuarem em conjunto. As equipes móveis são colocadas do ponto de vista formal sob a autoridade do dirigente escolar, que nomeia um conselheiro de segurança. Os estabelecimentos educacionais contam com o Conselho Disciplinar e um conselho de segurança. Outros colegiados ao nível de prefeitura e de Departamento (este similar ao Distrito em Portugal e à Unidade Federativa no Brasil) têm sido organizados para traçar diretivas e integrar as ações nas áreas da segurança pública, saúde escolar e outras. O Ministério da Educação Nacional tem mantido um registro eletrônico de ocorrências em todo o país, que são processadas e analisadas centralmente (FRANÇA, [2011?]). 
Quanto ao Brasil, conta com a Polícia Federal, que trata dos crimes capitulados como federais (ex., tráfico de armas), ao passo que cada Estado e o Distrito Federal tem a Polícia Militar, incumbida em especial da vigilância ostensiva e da intervenção em situações de insegurança, e a Polícia Civil, de funções investigativas. Os Municípios têm, ainda, a competência de criar a sua Guarda Municipal. No Distrito Federal, a Polícia Militar foi a primeira do país a constituir um Batalhão Escolar, com preparo específico na sua Academia.

Por conseguinte, conforme o país, diferentes soluções são adotadas, como se observa no Quadro 1, dando-se especial destaque ao Distrito Federal, no Brasil, sobre o qual estes autores têm pesquisado.

Quadro 1 - Relações entre escolas e polícias em três países.

\begin{tabular}{|l|l|l|l|}
\hline \multicolumn{1}{|c|}{ Características } & \multicolumn{1}{|c|}{ Brasil } & \multicolumn{1}{c|}{ Portugal } & \multicolumn{1}{c|}{ França } \\
\hline Tipo de Estado & Federativo. & Unitário. & Unitário. \\
\hline Redes escolares & $\begin{array}{l}\text { Federal, estaduais, } \\
\text { municipais e parti- } \\
\text { culares. }\end{array}$ & $\begin{array}{l}\text { Escolas públicas, } \\
\text { cooperativas e } \\
\text { particulares stricto } \\
\text { sensu }\end{array}$ & $\begin{array}{l}\text { Rede nacional de } \\
\text { escolas públicas } \\
\text { (nacionais) e pri- } \\
\text { vadas. }\end{array}$ \\
\hline $\begin{array}{l}\text { Polícias mais perti- } \\
\text { nentes }\end{array}$ & $\begin{array}{l}\text { Polícias Militar } \\
\text { e Civil em cada } \\
\text { Unidade Federativa; } \\
\text { Guardas Municipais } \\
\text { facultativas. }\end{array}$ & $\begin{array}{l}\text { PSP, GNR e Polícias } \\
\text { Municipais. }\end{array}$ & $\begin{array}{l}\text { Gendarmerie e } \\
\text { Polícia Nacional. }\end{array}$ \\
\hline Gestão educacional & $\begin{array}{l}\text { Rede federal } \rightarrow \\
\text { Ministério da Edu- } \\
\text { cação } \\
\text { Redes estaduais } \rightarrow \\
\text { Secretarias de Edu- } \\
\text { cação das Unidades } \\
\text { Federativas } \\
\text { Redes municipais } \\
\text { Secretarias munici- } \\
\text { pais de Educação. }\end{array}$ & $\begin{array}{l}\text { Ministério da } \\
\text { Educação e suas } \\
\text { delegações. }\end{array}$ & $\begin{array}{l}\text { Ministério da Edu- } \\
\text { cação Nacional e } \\
\text { suas delegações. }\end{array}$ \\
\hline $\begin{array}{l}\text { Segurança na escola } \\
\text { (além das funções } \\
\text { dos educadores) }\end{array}$ & $\begin{array}{l}\text { No DF, vigias } \\
\text { contratados para } \\
\text { segurança patrimo- } \\
\text { nial; funcionários } \\
\text { não docentes para } \\
\text { disciplina. }\end{array}$ & $\begin{array}{l}\text { Quadro específico } \\
\text { de segurança esco- } \\
\text { lar do Ministério da } \\
\text { Educação. }\end{array}$ & $\begin{array}{l}\text { Funcionários não } \\
\text { docentes em pe- } \\
\text { queno número, em } \\
\text { face de cortes de } \\
\text { pessoal. }\end{array}$ \\
\hline
\end{tabular}

(Continua) 
Conclusão

\begin{tabular}{|l|l|l|l|}
\hline $\begin{array}{l}\text { Responsabilidade } \\
\text { maior no estabeleci- } \\
\text { mento }\end{array}$ & $\begin{array}{l}\text { Diretor e, em parte, } \\
\text { conselho escolar } \\
\text { quando constituído. }\end{array}$ & $\begin{array}{l}\text { Diretor e, em } \\
\text { parte, colegiados } \\
\text { escolares. }\end{array}$ & $\begin{array}{l}\text { Diretor e, em parte, } \\
\text { conselhos escolares, } \\
\text { especialmente Con- } \\
\text { selho Disciplinar. }\end{array}$ \\
\hline $\begin{array}{l}\text { Atuação da(s) } \\
\text { polícia(s) mais } \\
\text { pertinente(s) }\end{array}$ & $\begin{array}{l}\text { No DF, parceria: } \\
\text { ronda policial militar } \\
\text { móvel + policial(is) } \\
\text { fixos em estabeleci- } \\
\text { mentos prioritários. } \\
\text { Batalhão especiali- } \\
\text { zado, com preparo } \\
\text { suplementar na } \\
\text { Academia. }\end{array}$ & $\begin{array}{l}\text { Fiscalização dos } \\
\text { espaços públicos. } \\
\text { Atende a chama- } \\
\text { dos, dependendo } \\
\text { da autoridade } \\
\text { maior do diretor. } \\
\text { Programa Escola } \\
\text { Segura. }\end{array}$ & $\begin{array}{l}\text { Parceria intermi- } \\
\text { nisterial. Policial } \\
\text { referente para } \\
\text { escola. Rondas nos } \\
\text { espaços públicos. } \\
\text { Atuação na escola } \\
\text { em princípio sob } \\
\text { a autoridade do } \\
\text { diretor. Segundo } \\
\text { noticiário, pode } \\
\text { atuar a chamado } \\
\text { (do/em nome do } \\
\text { diretor) ou por } \\
\text { iniciativa própria } \\
\text { (ex., abordagem } \\
\text { de filhos de sans } \\
\text { papiers). }\end{array}$ \\
\hline & & & \\
& & & \\
& & & \\
\hline
\end{tabular}

Fonte: os autores (2013).

Conquanto a presença do policial na escola seja importante na proteção e segurança, dentro ou nas imediações da mesma, há que distinguir entre o relacionamento formal e informal. Ao contrário de Portugal e da França, o Brasil, como Estado federativo de amplo território, tem serviços públicos predominantemente descentralizados. $\mathrm{O}$ mesmo ocorre com as parcerias locais entre autoridades educacionais e policiais em países federativos continentais, como o Canadá e a Austrália. Portugal e França, como Estados unitários, tendem a centralizar os serviços em suas capitais: as redes escolares e as polícias são nacionais, não federais. No Brasil buscam-se soluções conforme as características das Unidades Federativas. Algumas adotaram, com modificações, a experiência do Batalhão Escolar na sua respectiva Polícia Militar. Há também projetos de polícias e de guardas municipais, nem todos alvos de pesquisas. Dos três países Portugal mantém um quadro próprio de funcionários, preferentemente ex-policiais, no seu Ministério da Educação para a segurança das escolas. O Brasil é um dos países que, em certas circunstâncias e áreas, aloca policiais fixos a escolas. Deseja-se, em princípio, que o policial fixo ou os policiais de ronda sejam conhecidos pela escola e estabeleçam relações com os educadores e educandos. Nesse caso, além de desempenharem funções específicas de polícia, também se espera que participem 
mais ou menos indiretamente do processo pedagógico da escola, aconselhando, orientando e alertando os alunos sobre as consequências das práticas ilícitas e comportamentos errôneos adotados durante a adolescência e a juventude.

\section{Da estrutura à prática}

A atuação policial se inclui num quadro institucional mais amplo, mas os projetos e relações sociais se desenrolam no dinamismo da realidade social. Numa resenha seletiva da literatura, destaca-se que, em países como os Estados Unidos, Austrália e Canadá, a presença policial é cada vez mais frequente nas escolas. No primeiro $47,8 \%$ dos estabelecimentos teriam um policial destacado, desempenhando sobretudo as funções tradicionais de repressão (BEAUMONT; GARCIA, 2010). No entanto, cada vez mais os policiais são convidados a tomar parte em programas escolares para prevenir a violência ou a criminalidade juvenil. Em ampla resenha da literatura, Beaumont e Garcia (2010) constataram que os resultados da presença policial em meio escolar são mistos no que tange à diminuição da criminalidade e da violência. Para aprofundar o estudo das relações polícia - escola efetuaram uma pesquisa documental comparativa sobre mais de 60 textos de parcerias de vários países, em especial dos Estados Unidos, Canadá, França, Espanha e Reino Unido. Suas conclusões apontam que a eficácia depende da qualidade dos acordos, em especial quando os parceiros discutem e definem as responsabilidades de cada um, quando estabelecem um glossário comum e dedicam tempo para identificar as situações que, segundo as partes, requerem a intervenção policial. Entretanto, raramente tais documentos incluíam a avaliação da parceria. Assim, os resultados positivos dependem de entendimentos claros, levando em conta os fatores humanos (personalidades, habilidades de comunicação das pessoas envolvidas), organizacionais (planejamento do tempo, disponibilidade dos parceiros, locais adaptados às intervenções policiais) e contextuais (meio socioeconômico, clima da comunidade e da escola e natureza das intervenções).

Em Portugal, a avaliação de Cezário (2009) mostra a busca de inovação da PSP, em consonância com as orientações da União Europeia, ao adotar em 2006 o PIPP - Programa Integrado de Policiamento de Proximidade, com ações mais voltadas para o trato com os jovens, envolvendo as equipes do Programa Escola Segura (então a ele incorporado) e as Equipes de Apoio à Vítima. O Programa Escola Segura é uma ponte, com as vertentes operacional e pedagógica, visando a promover uma cultura de segurança nas escolas, além de fomentar o civismo e a 
cidadania. Os policiais são voluntários e, apesar de não terem formação específica e contínua, promovem palestras, visitas, demonstrações e eventos desportivos. O nível de satisfação dos profissionais era elevado e, dentro do PIPP, apontavam a mudança da imagem do policial junto aos jovens. Todavia, fora do Projeto, os policiais percebiam os jovens como pessoas que tinham grandes dificuldades para acatar a autoridade, já que a sua tendência era de rebeldia. Com isso, as relações jovens - policiais eram cheias de lacunas, ora satisfatórias, ora desgastadas.

Do lado das escolas, Sebastião, Campos e Merlini (2012) assinalaram a tendência recente de estabelecer políticas de regulação dos comportamentos, por meio de sucessivas reformulações doEstatuto do Aluno (lei sobre os comportamentos dos alunos, entre outras matérias) e as tentativas de criminalização do bullying. Nas suas incursões à empiria, os pesquisadores selecionaram três aglomerados de escolas da área metropolitana de Lisboa, verificando que, na forte competição por atrair alunos (potencialmente bem sucedidos, para elevarem o desempenho do estabelecimento na avaliação externa), as escolas se autodefiniam, reinterpretando leis e normas de modos diferenciados. Constataram que, tendo em vista os interesses de manter a sua reputação e atrair discentes, despreocupavamse de relatar certas ocorrências de violência ao Ministério da Educação, ao passo que, noutros casos, a categorização das mesmas era uma para o Ministério e outra para a Comissão de Proteç̧ão de Crianças e Jovens, um órgão não judiciário. A visão mais frequente era a de que a violência vinha de fora da escola. Quanto à relação com a comunidade e os parceiros locais, a mais representativa era a de obter a colaboração deles para resolver seus problemas cotidianos de violência. Desse modo, no caso da Escola Segura, seus agentes eram chamados a resolver pontuais incidentes de violência e criminalidade. Só alguns estabelecimentos escolares estabeleciam com a comunidade e os agentes locais real parceria para superar a violência escolar.

Por sua vez, o Brasil apresenta um leque de experiências no sentido de estabelecer pontes entre escola e polícia, defrontando-se frequentemente com as divergentes perspectivas dos jovens pelos policiais e vice-versa, bem como com o dissenso em face da presença da polícia na escola, ora considerada necessária, ora intimidadora. Diversas iniciativas têm sido focalizadas por pesquisas, das quais selecionamos algumas.

O Estado de Minas Gerais executa ou executou diversos projetos, entre eles o Programa Educacional de Repressão às Drogas e à Violência (PROERD), criado em 1998, de caráter interdisciplinar, com a participação de policiais fardados 
nas escolas em atividades educacionais. Outro foi o Programa Anjos da Escola, analisado por Windson (2008), que foi adotado no policiamento das escolas de Belo Horizonte, sem uso de uniforme e porte de arma, depois de uma série de debates prévios, em que se patenteou a impossibilidade de os estabelecimentos educacionais solucionarem isoladamente parte dos problemas de violência. O nome do projeto expressa um esforço para construir o policial como ser transcendente, o que talvez tenha agravado os paradoxos e contradições e, segundo o autor, não eliminou a ambiguidade matricial de temor da polícia, com a sua imagem e, em certos casos, comportamentos excessivos, e, de outro lado, a busca para formar uma polícia humanizada, que exerça funções também educativas. Os resultados indicaram apoio dos educadores, mas o dissenso dos alunos, entre os sentimentos de intimidação e medo e de maior segurança produzidos pela presença policial. Foi constatado que as experiências desenvolvidas pela Polícia Militar nas escolas a partir de 1988 geraram um conjunto relevante de saberes e poderes que precisavam ser sistematizados. Com efeito, este é um ponto crucial, já que também para a polícia o ambiente escolar é pleno de desafios desconhecidos.

Outra experiência focalizada foi a do projeto de Patrulha Escolar Comunitária nas escolas estaduais do Paraná, conforme parceria firmada em 2003. Stival (2011) pesquisou duas escolas da periferia da Capital, verificando que na dinâmica escolar prevalecia a "cultura do medo", já que as unidades educacionais usavam elementos coercitivos e autoritários para lidar com certos problemas da prática educativa. Ao aparecerem de vez em quando, os policiais, na visão de uma parte dos alunos, apenas reforçavam tal cultura, por meio de postura considerada autoritária, com revistas e interrogações na entrada dos estabelecimentos, que só aumentavam o sentimento de insegurança. Para a maior parte dos professores, contudo, as brigas entre alunos e outros problemas requeriam a presença policial. Além dessa função repressiva, a pesquisadora constatou que os policiais se esforçavam para atuar numa instituição desconhecida, enfrentando valores divergentes e que, num dos estabelecimentos, haviam levado a efeito um ciclo de palestras sobre trânsito, violência e drogas.

Silva (2010) pesquisou o mesmo projeto num município da Região Metropolitana da Capital. Os dados registraram a crise da autoridade escolar, que apresentava como pressupostos básicos a crise de convivência, a descrença no trabalho docente e o desenvolvimento de sociabilidade violenta entre os jovens. A retroalimentação destes elementos legitimava a entrada da polícia nas escolas, 
para suprir as dificuldades de controle destas. Com isso, não só se transferia parte das responsabilidades escolares aos policiais, como se reforçava um controle social autoritário, num "contexto de anomia, desordem, descrença e desgaste" (SILVA, 2010, p. 110). Considerando ser uma área com alta exclusão social e de fracasso dos alunos em escola precária, pode-se interpretar que a experiência, no caso em tela, buscava estabelecer a ordem mediante recursos repressivos mais fortes, na impossibilidade de ir às raízes e superar o mal estar de educadores e educandos com a crise institucional.

Em outra experiência, Soares (2012) encontrou resultados positivos no projeto "Jovens Construindo Cidadania", levado a efeito por parceria entre as escolas e a Guarda Municipal de Barueri, Região Metropolitana de São Paulo. Atuando dentro das escolas com a orientação da pedagogia social, na qualidade de educadores sociais, conseguiram mudar a imagem de truculência e repressão junto aos atores escolares.

\section{Educadores \& policiais: papéis superpostos?}

A complexidade das questões de segurança escolar levaram, por sua vez, o Distrito Federal em 1989 à criação do Batalhão Escolar na sua Polícia Militar, com agentes preparados pela sua Academia para atuar nos estabelecimentos educacionais, em rondas ou com a presença fixa durante o tempo letivo ou parte dele, dependendo do grau de risco. Como parte de uma pesquisa qualitativa mais ampla, em cinco escolas de periferia consideradas violentas, Santana e Gomes (2010) detiveram-se na atuação policial, já que, pelos riscos constatados, quase todas tinham pelo menos um policial fixo.

Recordemo-nos de que, como burocracias públicas, a polícia e a escola correspondem ao tipo ideal definido por Weber (1968), Merton (1973) e outros autores: autoridade legal, ordem impessoal, estrutura hierárquica, documentos escritos, obediência baseada na lei e no regulamento etc. Entretanto, embora integrante do Estado, instituições como a escola têm características altamente diferenciadas, por educar crianças e adolescentes, ter alto grau de informalidade nas relações sociais, apresentar elevado número de situações sociais inesperadas e complexas, não se dedicar à produção de bens e seguir teorias pedagógicas que inserem o aluno como sujeito protagonista da aprendizagem e do processo educativo. Por isso mesmo, a escola pode ser explicada não apenas pelo tipo ideal 
de burocracia, ensejando-se várias imagens organizacionais, a exemplo da escola como democracia, arena política, anarquia e cultura, além de outras alternativas possíveis (COSTA, 1996; GOMES, 2005). Dessa forma, os contatos duradouros e cotidianos entre policiais, educadores e educandos pode polir uma série de arestas do comportamento formal, abrindo possibilidades de um relacionamento social menos categórico e mais simpático. Desse modo, a presente investigação, de caráter exploratório, nessa vertente se norteou por várias indagações: como os membros da comunidade escolar avaliavam a atuação do policial? Com a inserção do policial no estabelecimento educacional, como agiam e reagiam outros atores escolares? Como educadores e policiais delimitavam os seus papéis?

Os dados indicaram que apenas $9,6 \%$ dos professores e $10,6 \%$ dos alunos haviam buscado a ajuda dos policiais quando foram vítimas de violência na escola, isto é, constituía a última instância a ser procurada. Porém, eles classificaram o trabalho do policial como eficiente, pois transmitia tranquilidade, contribuía para manter a ordem e a segurança de todos, concordando com os relatos de Gonçalves e Spósito (2002, p. 114), ao afirmarem que "os problemas de violência na escola são vistos mais como questão de segurança e, portanto, passíveis de intervenção policial”.

Segundo os relatos dos diretores, os policiais os auxiliavam, resguardando e protegendo os alunos e a escola contra as gangues e depredações. Por isso, declararam que a violência dentro e fora da escola decresceu devido à chegada dos agentes. Estes apoiavam a direção sempre que solicitados, oferecendo um atendimento diferenciado à escola, pois eram considerados preparados para atender às emergências, conforme o depoimento de um diretor: “(...) O trabalho dele é diferente de um policial da rua porque ele lida com adolescente, com os funcionários da escola. Estão preparados para isso". Ademais, os diretores informaram que buscavam auxílio do policial porque os consideravam formados para lidar com situações conflituosas envolvendo os alunos e os profissionais da escola:

É um reforço que eu tenho aqui. Caso aconteça algo na escola, a primeira pessoa que tenho para pedir socorro são os policiais. Quando tem algum problema eu posso conversar com os policiais, eles me dão suporte e abertura (Diretor).

Essa constatação concorda com as de Ruotti (2006), justificando que, quando o assunto é de ordem mais grave, a escola não possui pessoas qualificadas e suficientes para controlar a violência, o que não oculta uma escalada de remédios 
repressivos para problemas de maior monta, da categoria de infrações e delitos. Embora os Conselhos Tutelares sejam órgãos estabelecidos pela legislação brasileira como uma instância antes da delegacia policial, constatou-se completo silêncio em relação a eles.

Todavia, apesar da ocorrência de infrações sérias que justificavam a intervenção policial, a pesquisa encontrou evidências de uma nebulosidade dos papéis de educador e policial, em que o primeiro transferia parte da autoridade para o último, ao menos como mecanismo (sexista, diga-se de passagem) de dissuasão de possível violência:

Já houve casos de chamar a gente para conversar com o aluno, às vezes a pessoa se exalta, não que não está dando conta da situação, mas é bom ter o apoio masculino, porque os alunos respeitam mais (...), porque geralmente os alunos são maiores do que qualquer professor ou professora. Geralmente ocorre isso de ter que chamar a gente para apoio moral para chegar, conversar (Relatos de diretores).

Em casos como estes, o policial, fardado e armado, pode exercer uma função dissuasiva, no sentido de desestimular ou intimidar o aluno. Desta forma, o agente passa a desempenhar uma função que não é típica do seu cargo. Esta confusão de atribuições também foi constatada, na presente pesquisa, como um "duplo papel" exercido pelos policiais, pois, além de transmitirem uma sensação de segurança, "atuavam igualmente como educadores", porque também orientavam, explicavam e aconselhavam os alunos e também os diretores: "Percebo que o policial conhece e tem familiaridade com os alunos. Ele sabe mais da vida dos alunos do que a gente e o aluno, quando vê o policial, trata normal, respeita e cumprimenta". (Relato de diretor).

Foi constatado que muitos policiais exerciam ações educativas informais dentro da escola, até promovendo atividades fora do horário de aula, o que era alvo de grande apreciação. No entanto, também se verificou que ao menos uma parte dos diretores se apoiava na transferência de parte da sua autoridade para o novo personagem, inserido na paisagem escolar. Com isso, o gestor escolar e outros educadores deixavam eventualmente de exercer a sua função propriamente educadora, disciplinadora e preventiva da violência. Nesse vácuo, o policial era chamado pela escola a ocupar espaços de educador, não reservando o policial para apenas a resolução dos problemas que tipicamente lhe cabiam. Em face desta 
renúncia a uma parte da sua autoridade, os educadores a longo prazo ficavam ainda mais fracos e com menor legitimidade perante os alunos e a comunidade. Os participantes do estudo informaram também que os policiais procuravam transmitir confiança aos alunos e que, algumas vezes, se tornavam seus confidentes. Querer falar e ser ouvido é parte do protagonismo do adolescente. Devido ao vínculo de amizade entre o policial e o aluno, muitas vezes o agente, pelas suas capacidades, exercia o papel de "conselheiro", oportunizando explicar aos alunos o que era certo e errado.

A maioria dos discentes relatou que já ouvira ou fora beneficiada com os conselhos do policial sobre como é o mundo do crime: "Aquela conversa, assim, não uma conversa de ameaçar o aluno (...), às vezes de orientar o aluno, que pode causar um maior problema para ele (...), ele pode ser fichado na delegacia e isso pode trazer problemas futuramente". (Relatos de alunos).

No entanto, se o policial passa a exercer esse papel, é de se indagar se os educadores profissionais estão utilizando a pedagogia do diálogo ou do monólogo. Ruotti (2006) descreve fato semelhante, pois no seu estudo o policial também se tornou confidente dos alunos, sendo simpático, entrando nas salas de aula, orientando os alunos sobre os malefícios das drogas e álcool. Essa nova função do policial, como cooperador da educação dos alunos, foi justificada e valorizada pela maioria dos entrevistados.

Com efeito, Abramovay e Rua (2004), Ruotti (2006) e Marques e colaboradores (2008) descrevem o policial na escola como um cooperador da tranquilidade e segurança para todos. Porém, eles também afirmam que essa presença reforça a incapacidade da direção em atender aos alunos tidos como violentos. Ratificando esta posição, Souto Maior Neto ([2010?], p. 6) declara que "os atos de indisciplina devem ser resolvidos no âmbito do próprio sistema educacional", em vez de pela polícia. Esses autores, por outro lado, observaram que muitos policiais eram convocados para resolverem assuntos de cunho pedagógico, não de contravenção ou crime e, até mesmo, para substituir ou exercer funções específicas de orientação e supervisão educacionais. Por sua vez, Carbone e Menin (2004) reforçam essa constatação, ao verificarem que a direção da escola mostra fraqueza quando necessita da ajuda do policial para a solução dos problemas disciplinares de discentes, tendo Moreira, Silveira e Andreoli (2006) atingido conclusões similares. 
A presente pesquisa confirmou que os policiais executavam na escola não somente funções específicas de segurança e proteção, mas também atividades consideradas pedagógicas, umas de natureza informal, que contribuíam para esclarecimento dos alunos e prevenção ou desvio do seu envolvimento com atividades ilegais, mas outras em que eram utilizados por educadores incautos para reforçar junto aos alunos a chamada "cultura do medo". Com isso, as ações educativas informais se contradiziam, criando uma confusão de valores, de imagens e de critérios de legitimação da autoridade. Isto era agravado, segundo depoimentos de alguns alunos, por agressões físicas por policiais e por omissões destes (diante de brigas), no interior da escola e fora da mesma.

Por isso, é indispensável cautela para não permitir que, com o estresse profissional, educadores abram mão das suas funções típicas e as transfiram para profissionais da segurança pública. Espera-se que o policial exerça um papel educativo informal. Nesta linha de convivência, de integração e mais longa interação social quotidiana, é maior a probabilidade de as relações se informalizarem e se afastarem das normas formais, o que efetivamente acontece. Afinal, cada escola tem a sua dinâmica social própria.

No caso do Distrito Federal, os entrevistados informaram que há quantidade insuficiente de agentes nas escolas, mas, ainda assim, houve diminuição dos atos violentos após a chegada do policial, passando a se sentirem mais seguros e protegidos. Antes as escolas eram apedrejadas e invadidas com frequência, o que, nos casos pesquisados, então não ocorrera mais.

Observou-se que uma minoria de professores e de alunos buscou o auxílio do policial quando sofreram algum tipo de violência na escola. Porém outra minoria, de professores, solicitou ajuda dos policiais quando o assunto estava relacionado à indisciplina de alunos, justificando-se com o acúmulo dos problemas de violência, que sobrecarregava a direção do estabelecimento. Os diretores, por sua vez, esclareceram que chamavam o policial ao interior da escola quando ocorriam atos violentos envolvendo os alunos, os professores ou o próprio diretor. Porém, apenas um gestor escolar não autorizava a circulação e permanência do policial no interior da escola e, por isso, eles estavam sempre posicionados no portão.

Outro momento em que o policial era solicitado pelos diretores se relacionava às revistas aos pertences dos alunos, no portão da escola ou nas salas de aula, quando havia denúncia de porte de armas e drogas ou de furtos de objetos pessoais dos outros alunos, ou quando aconteciam agressões entre alunos ou professores. 
Em nenhum momento os diretores relataram ou reconheceram que o policial estava "invadindo" o seu espaço ou "retirando" a sua autoridade. Os diretores ainda informaram que não interrompiam as conversas dos policiais com os alunos ou com algum membro da comunidade escolar e que não hesitavam em acionar os serviços do policial quando algum discente se alterava ou quando poderia partir para a agressão física.

Os diretores relataram, ainda, que atendiam aos chamados dos professores nas salas de aula em casos de brigas ou discussões, porém, caso percebessem que as ocorrências eram graves, solicitavam o auxílio do policial e este prontamente atendia, fosse para retirar o aluno de sala, repreendê-lo ou aconselhá-lo, autorizando-o a conduzir o aluno à Delegacia da Criança e do Adolescente quando o caso de violência era considerado grave.

Quanto aos policiais, destacaram a acessibilidade dos alunos, informando que, a partir do momento em que as barreiras do medo eram quebradas, muitos estudantes escolhiam o policial para servir de "conselheiro", "amigo" e até "confidente". Nesse momento, o policial aproveitava para estabelecer laços afetivos, alertando sobre os malefícios das drogas, fumo e álcool e do crime, executando, assim, ações preventivas contra a violência.

Os dados mostram que a área cinzenta entre os papéis profissionais estava repleta de filigranas, refletindo falta de clara identidade, com riscos significativos, entre estes a autoconfissão explícita ou implícita de incapacidade dos educadores, que recuam em sua autoridade. Enquanto isso, os policiais passam a cumprir as tarefas menos "simpáticas" do estabelecimento na manutenção da ordem, isto é, tornam-se os bad guys, em prol dos "mocinhos", os educadores, numa espécie de "divisão moral do trabalho". Esta neblina deve ser rigorosamente evitada, por esvaziar a autoridade escolar e conduzir o policial a exercer missões que não são tipicamente suas. Se o policial age como um valioso educador informal ou social, não interessa à sociedade ou ao sistema de ensino a desobrigação dos educadores formais, nem os desvios de funções.

\section{Tensões latentes ou explícitas}

O pulsar das tensões no caso do Distrito Federal, apontando que estas situações não se caracterizam pela simplicidade, é revelado por outra pesquisa realizada junto a agentes do mesmo Batalhão Escolar, assim que ingressavam em curso sobre Juventude 
e Direitos Humanos oferecido pela Universidade Católica de Brasília e pela UNESCO (SOUSA; GOMES, 2011). Ressalte-se que, além do preparo específico da sua Academia, os agentes, incluindo os praças, apresentavam alto nível de escolaridade. Sem que se possam fazer generalizações, os dados patenteiam a oposição manifesta ou latente entre policiais e jovens. Para os primeiros, estes últimos estavam associados na perspectiva dos primeiros ao perigo, violência, rebeldia, irresponsabilidade e ousadia e eram identificados em grande parte pela moda e pela aparência. Verificaram-se tendências, conquanto estatisticamente não significativas, de: 1) quanto menor a escolaridade, maior percepção negativa dos jovens; 2) quanto menor a escolaridade e maior o tempo de serviço, maior a identificação dos jovens pela moda e aparência.

Ora, as formas de vestir geram mapas de significado social, constituindo, no caso da juventude, uma forma de expressão protagônica. Pais (2008) vai mais além, ao interpretar os estilos juvenis como reação dos jovens à situação de marginalidade ou subalternidade. A falta do protagonismo no trabalho, em face do elevado desemprego juvenil; o fracasso escolar e a afirmação no consumo (quando a renda o permite) conduzem à assunção de identidades variadas, fabricadas em torno de imagens e estilos, que constituem rituais de resistência. Estas mesmas máscaras se aplicam às escolas periféricas, frequentadas por estudantes de baixa renda de minorias étnicas, consideradas "escolas de risco" ou "escolas do diabo". A competição entre os estabelecimentos para atrair "bons" alunos, manter sua "reputação" de segurança e assegurar pontos na avaliação externa foi o que constataram Sebastião, Campos e Merlini (2012). Idênticos processos já foram constatados nas áreas urbanas francesas, com a formação, nas periferias, das escolas "latas de lixo", às quais são relegados os "piores" alunos (PAYET, 1996; FELOUZIS; PERROTON, 2007), em face da divisão moral do trabalho entre educadores, isto é, o "nobre" trabalho de ensinar e o trabalho "sujo" de disciplinar os alunos com tendência à exclusão (no caso aqui analisado, este último em parte transferido aos policiais). Conforme resenha de Sousa e Gomes (2011), a moda e a aparência, além de características físicas, como o sexo e a cor da pele, bem como a presença do jovem em áreas degradadas e a sua matrícula em escolas "mal reputadas", tornam parte dos jovens internacionalmente alvos preferenciais de revistas e abordagens policiais, não raro violentas, por critérios de eficiência que, entretanto, se traduzem em discriminação social, étnica, econômica, etária e de sexo. Como quem muito procura, acha, pode deixar de procurar alvos que, na sombra do esquecimento, podem praticar infrações mais graves. A "violência de presunção" se traduz em predição que leva à perdição (PAIS, 2008). As imagens negativas recíprocas de policiais e jovens, em parte fundamentadas em fatos, cavam, pois, um abismo de indispensável superação, para que o círculo vicioso não mergulhe numa longa espiral descendente. 


\section{Novas indagações}

Retornando aos casos de Portugal e da França seria, sob todos os aspectos, interessante pesquisar como se desenvolvem as relações entre agentes policiais e atores escolares e em que medida se afastam das normas burocráticas oficiais, baixadas em regulamentos, resoluções, protocolos e outros documentos, como, do lado da escola, constataram Sebastião, Campos e Merlini (2012). A burocracia é um tipo ideal, segundo Weber (1968), podendo, ao lado de outras correntes teóricas, formar diferentes imagens organizacionais da escola, conforme antes assinalado. Assim, o ideal busca esculpir a realidade, porém implica necessários desvios, ao encarnar em dinâmicas sociais diversificadas, já que, dizendo tautologicamente, o ideal é ideal e não real. No caso da República Portuguesa seria particularmente desafiador conhecer as implicações do esprit de corps dos ex-policiais quando agem como membros do quadro do Ministério da Educação, em suas relações com educadores, educandos e também com os seus ex-colegas de corporação. Outro aspecto interessante é a maneira como as populações, nesses países, interagem com as várias polícias.

No caso da Capital federal brasileira, a formação e o aparar das arestas entre escola e polícia implica a reinterpretação em diferentes situações sociais das normas burocráticas públicas. Sem desejar cair no lugar comum de explicações generalizantes, cabe lembrar o famoso “jeitinho brasileiro", considerado por Sérgio Buarque de Holanda (1963) como parte da herança colonial lusitana. Além de possíveis interpretações segundo as diversificadas paisagens culturais brasileiras, é consenso de grande parte da literatura que a escola se afasta amplamente dos modelos clássicos de organização, sendo, aliás, categorizada como instituição, como antes foi notado. Logo, os contatos diuturnos entre os atores da escola e os policiais, a cujos papéis militares se acrescenta intencionalmente o de "educador informal", como o que organizou torneios de futebol fora do seu horário de trabalho, para melhor ocupar o tempo livre dos alunos, modifica e, em parte, informaliza as relações sociais. Reiterando a burocracia como tipo ideal e as características sociológicas da escola, certamente em Portugal, França e outros países, as relações com a polícia provavelmente apresentarão nuanças bem particulares, conforme o meio social, o tamanho da escola e outros fatores. Interessante tema a estudar. 


\section{Referências}

ABRAMOVAY, M.; RUA, M. G. Violências nas escolas. Brasília: UNESCO, 2004.

ARROYO, M. G. Quando a violência infanto-juvenil indaga a pedagogia. Educação \& Sociedade, Campinas, v. 28, n. 100 - Especial, out. 2007. p. 787-807.

BEAUMONT, C.; GARCIA, N. Partenariat entre la police et l'école : analyse des modalités de partenariat entre les milieux scolaires et policiers pour prevenir la violence et la criminalité chez les jeunes. Raisons: Comparaisons. Éducations: la revue française d'éducation comparée, Paris, n. 6, p. 207-242, dez. 2010.

CALDAS, D. B. Violências em sala de aula na educação superior: percepções de docentes de instituições particulares de São Luís do Maranhão. Brasília. 2012. 89 f. Dissertação (Mestrado)- Programa de Pós-Graduação em Educação, Universidade Católica de Brasília, Brasília, 2012.

CARDOSO, J. C. As vantagens da comparação jurídica de sistemas. Revista da Faculdade de Ciências Humanas e Sociais, Porto (Portugal), n. 1, p. 145150, 2004. Disponível em: <https://bdigital.ufp.pt/dspace/handle/10284/620>. Acesso em: 25 jan. 2011.

CARBONE, R. A.; MENIN, M. S. S. Injustiça na escola: representações sociais de alunos do ensino fundamental e médio. Educação \& Pesquisa, São Paulo, v. 30, n. 2, maio/ago. 2004. Disponível em: <http://www.scielo.br/ scielo.php? script $=$ sci_arttext\&pid $=$ S1517-97022004000200004\&lng=en\&nr $\mathrm{m}=\mathrm{iso}>$. Acesso em: 25 maio 2010.

CEZÁRIO, K. F. S. Os jovens em Portugal e a Polícia de Segurança Pública (PSP) - um policiamento orientado para a cidadania: o Programa Integrado de Policiamento de Proximidade. Revista Brasileira de Segurança Pública, São Paulo, v. 3, n. 4, p. 56-71, fev./mar. 2009.

COON, J. K. The adoption of crime prevention technologies in public schools. [S.l.: s.n], 2005. Disponível em: <http://de.scientificcommons.org/8673730>. Acesso em: 25 maio 2010. 
COSTA, J. A. Imagens organizacionais da escola. Porto: Asa, 1996.

CHRISPINO, A.; CHRISPINO, R. S. P. A judicialização das relações escolares e a responsabilidade civil dos educadores. Ensaio: Avaliação e Políticas Públicas em Educação, Rio de Janeiro, v. 16, n. 58, p. 9-30, jan./mar. 2008.

CHRISPINO, A.; LAMEGO, M. Visão e políticas integradas no atendimento à violência escolar ou por que os males de Pandora não se resolvem com D.Quixote. In: GOMES, C. A.; FERREIRA, G. A.; KOEHLER, S. M. F. (Org.). Culturas de violência, culturas de paz : da reflexão à ação de educadores, operadores do Direito e defensores dos direitos humanos. 1 ed.Curitiba (PR): Editora CRV, 2012.

DEBARBIEUX, É. Violência na Escola: um desafio mundial?. Lisboa: Colecção Horizontes Pedagógicos, Instituto Piaget, 2006.

DEVINE, J. A mercantilização da violência escolar. In: DEBARBIEUX, É.; BLAYA, C. (Org.). Violência nas escolas e políticas públicas. Brasília: UNESCO, 2002. p. 207-223.

DIREITO, C.A.M. O jovem Pedro Calmon. [S.l.: s.n., 2010?]. Disponível em: $<$ http://bdjur.stj.gov.br/xmlui/bitstream/handle/2011/9703/O_Jovem_Pedro_ Calmon.pdf?sequence=1. . Acesso em: 25 maio 2010.

DUBET, F. Le declin de l'institution. Paris: Éds. du Seuil, 2002.

FELOUZIS, G.; PERROTON, J. Les "marchés scolaires": une analyse em termes d'économie de la qualité. Revue Française de Sociologie,[França], v. 48, n. 4, p. 693-722, 2007.

FRANÇA. Ministère de l'Éducation Nationale, Jeunesse et Vie Associative. Les politiques éducatives: La prévention et la lutte contre la violence. França: [s.n, 2011?]. Disponível em: <http://www.education.gouv.fr/cid2765/laprevention-et-la-lutte-contre-la-violence.html>. Acesso em: 25 jan. 2011.

GOMES, C. A. A escola de qualidade para todos: abrindo as camadas da cebola. Ensaio: Avaliação e Políticas Públicas em Educação, Rio de Janeiro, v. 13, n. 48, jul./set. 2005. p. 281-306. 
GOMES, C. A. et al. Violência na ótica de alunos adolescentes do Distrito Federal. Cadernos de Pesquisa, São Paulo, v. 36, n. 127, 2006. p. 11-34.

GONÇALVES, L. A. O.; SPOSITO, M. F. Iniciativas públicas de redução da violência escolar no Brasil. Cadernos de Pesquisa, São Paulo, n. 115, p. 101138, mar. 2002.

HOLANDA, S. B. Raízes do Brasil. 4. ed. Brasília: Editora da Universidade de Brasília, 1963.

MARQUES, A. P. S. et al. A atuação da polícia na resolução dos conflitos no espaço educacional: uma alternativa ou um problema?. In: CONGRESSO NACIONAL DE SEGURANÇA PÚBLICA, 2., 2008, Maceió; CONFERÊNCIA NACIONAL DE SEGURANÇA PÚBLICA, 2., 2008, Maceió. Anais... Maceió: CONNASP; CONESP, 2008. Disponível em: $<$ http://www.gepsojur.org/anaisconnasp/eixos/GSC-31.pdf>. Acesso em: 25 maio 2010.

MERTON, R. K. Estrutura social e socialização. In: PEREIRA, L.; FORACCHI, M. M. (Org.). Educação e sociedade. São Paulo: Nacional, 1973, p. 287-320.

MOREIRA, F. G.; SILVEIRA, D. X.; ANDREOLI, S. B. Situações relacionadas ao uso indevido de drogas nas escolas públicas da cidade de São Paulo. Revista Saúde Pública, São Paulo, v. 40, n. 5, out. 2006. Disponível em: $<$ http://www.scielosp.org/scielo.php? script=sci_arttext\&pid=S0034$89102006000600010 \& \operatorname{lng}=\mathrm{en} \& n \mathrm{~mm}=\mathrm{iso}>$. Acesso em: 25 maio 2010.

PAIS, J. M. Máscaras, jovens e "escolas do diabo". Revista Brasileira de Educação, Rio de Janeiro, v. 13, n. 37, p. 7-21, jan./abr. 2008.

PAYET, J. P. Le "sale boulot": division morale du travail dans un collège de banlieue. Annales de la Recherche Urbaine, Paris, n. 75, p. 19-31, mar. 1996. Disponível em : <http://www.annalesdelarechercheurbaine.fr/IMG/pdf/Payet_ ARU_75.pdf>. Acesso em: 24 nov. 2011.

PORTUGAL. Ministério da Educação. Segurança nas escolas.

Portugal: [s.n., 2011?]. Disponível em: $<$ http://www.min-edu.pt/index. php?s=white\&pid=107>. Acesso em: 25 jan. 2011. 
POLÍCIA DE SEGURANÇA PÚBLICA. Programas Especiais: Escola Segura. Portugal: [s.n., 2010?]. Disponível em: $<$ http://www.psp.pt/Pages/ programasespeciais/escolasegura.aspx?menu=4>. Acesso em: 20 jan. 2011.

RUOTTI, C. Conflito e insegurança escolar nas zonas Leste e Sul no município de São Paulo. In: RUOTTI, C.; ALVES, R.; CUBAS, V. O. Violência na escola: um guia para pais e professores. São Paulo: Andhep; Imprensa Oficial do Estado de São Paulo, 2006. p. 55-105.

SANTANA, E. M. U.; GOMES, C. A. Polícia e escola: aparando arestas. Contrapontos, Joinville, v. 10, n. 2, p. 156-165, maio/ago. 2010. Disponível em: <http://www6.univali.br/seer/index.php/rc/article/view/2075/1633>. Acesso em: 17 jan. 2013.

SEBASTIÃO, J.; ALVES, M. G.; CAMPOS, J. Violência na escola e sociedade de risco: uma aproximação ao caso português. In: SEBASTIÃO, J. (Org.). Violência na escola: tendências, contextos, olhares. Coimbra: Cosmos; Santarém: Escola Superior de Educação de Santarém, 2011.

SEBASTIÃO, J.; CAMPOS, J.; MERLINI, S. Processos de regulação da violência escolar: das políticas às práticas. In: CONGRESSO PORTUGUÊS DE SOCIOLOGIA, 7., 2012, Porto. Trabalhos apresentados.... Porto (Portugal): Universidade do Porto, 2012. p. 1-14. Disponível em: $<$ http://www.academia. edu/2076884/Processos_de_Regulacao_da_violencia_escolar_-_das_politicas_as_ praticas_Sebastiao_Campos_e_Merlini>. Acesso em: 17 jan. 2013.

SILVA, R. B. Educação e controle social: a intervenção policial na escola. Curitiba, 2010. 132f. Dissertação (Mestrado)- Programa de Pós-Graduação em Sociologia, Universidade Federal do Paraná, Curitiba, 2010.

SOARES, J. N. O. A Guarda Municipal e sua interface com a escola. Revista Diálogos: pesquisa em extensão universitária,Brasília, DF, v. 17, n. 1, p. 8492, jun. 2012.

SOUSA, C. A. M.; GOMES, C. A. C. A juventude na ótica de policiais: a negação do direito na aparência. Linhas Críticas, Brasília, DF, v. 17, n. 34, p. 527-543, set./dez. 2011. 
SOUTO MAIOR NETO, O. S. Doutrina: ato infracional, medidas sócioeducativas e o papel do sistema de justiça na disciplina escolar. Rio Grande do Sul: Ministério Público, [2010?]. Disponível em: <http://www.mp.rs.gov.br/ infancia/doutrina/id153.htm>. Acesso em: 25 maio 2010.

STIVAL, M. C. E. E. Políticas públicas do Estado do Paraná: uma análise da violência nas escolas públicas e o trabalho da Patrulha Escolar Comunitária. In: SIMPÓSIO BRASILEIRO DE POLÍTICA E ADMINISTRAÇÃO DA EDUCAÇÃO, 25., 2011, São Paulo. Anais... São Paulo: Anpae, 2011. Disponível em: <http://www.anpae.org.br/simposio2011/cdrom2011/PDFs/ trabalhosCompletos/posters/0095.pdf>. Acesso em: 16 jan. 2013.

THOMAS, S. P.; SMITH, H. School connectedness, anger behaviors, and relationships of violent and nonviolent American youth. Perspectives in Psychiatric Care, Farmington, CT, v. 40, n. 4, p. 135-148, out./dez. 2004.

WEBER, M. Economy and society: an outline of interpretive sociology. Nova Iorque: Bedminster, 1968.

WINDSON, J. M. O. A policialização da violência em meio escolar. Belo Horizonte, 2008. 244 f. Tese (Doutorado)- Faculdade de Educação, Universidade Federal de Minas Gerais, Belo Horizonte, 2008.

Recebido em: 23/01/2013

Aceito para publicação em: 20/08/2013

\section{School and police in three countries: old wine in new bottles or the crisis of institutions Abstract}

School and police in three countries: new wine into old wineskins or the crisis of the institutions. The international spread of school violence has led to the increasing participation of police agents in its premises. This paper analyses the bridges built between school and police in Brazil, Portugal and France, in the so called institutional crisis of post-modernity. The comparison among these countries reveals that these relations develop in the constitutional and public managerial framework of each one. However, laws and regulations are 
reinterpreted in the social reality, often generating differences in relation to the bureaucracy's ideal type. In this dynamic, we found significant deviations and role overlapping of educators and agents. Several projects have aimed to overcome the gap between police agents and youths, since their roles and appearances oppose themselves reciprocally, according to stereotypes not seldom founded on facts. We propose issues for further research.

Keywords: Police. School safety. School violence. School management. Prejudice.

\section{Escuela y policía en tres países: vino nuevo en botillos viejos o la crisis de las instituciones Resumen}

La expansión internacional de la violencia escolar ha llevado la presencia policial a los establecimientos educativos y está aumentando cada vez más. Este trabajo analiza puentes construidos entre escuela y policía en Brasil, Portugaly Francia en tiempos de la llamada crisis institucional postmoderna. Se verifica que tales relaciones se desarrollan según cuadros constitucionales y de acuerdo con la administración pública de cada país, y las normas se reinterpretan en la realidad social, lo que lleva a un alejamiento del tipo ideal burocrático. En esta dinámica se detectan significativos desvios y superposiciones de los roles de agentes y educadores. Varios proyectos han buscado superar el hiato entre policiales y jóvenes, ya que sus roles y apariencias se oponen, de acuerdo con estereotipos, a menudo, fundamentados en hechos. Se proponen cuestiones para ulterior investigación.

Palabras clave: Policía. Seguridad escolar. Violencia escolar. Gestión escolar. Prejuicios. 
